Article

\title{
OcUGT1-Catalyzing Glycodiversification of Steroids through Glucosylation and Transglucosylation Actions
}

\author{
Yan-Li Xu and Jian-Qiang Kong *(C) \\ Institute of Materia Medica, Chinese Academy of Medical Sciences \& Peking Union Medical \\ College (State Key Laboratory of Bioactive Substance and Function of Natural Medicines \& NHC Key \\ Laboratory of Biosynthesis of Natural Products), Beijing 100050, China; yanlixu@imm.ac.cn \\ * Correspondence: jianqiangk@imm.ac.cn; Tel.: +86-10-6303-3559
}

Academic Editor: Yasunori Yaoita

Received: 8 January 2020; Accepted: 21 January 2020; Published: 22 January 2020

\begin{abstract}
Steroidal glycosides are important sources of innovative drugs. The increased diversification of steroidal glycosides will expand the probability of discovering active molecules. It is an efficient approach to diversify steroidal glycosides by using steroidal glycosyltransferases. OcUGT1, a uridine diphosphate-D-glucose (UDP-Glc)-dependent glycosyltransferase from Ornithogalum caudatum, is a multifunctional enzyme, and its glycodiversification potential towards steroids has never been fully explored. Herein, the glycodiversification capability of OcUGT1 towards 25 steroids through glucosylation and transglucosylation reactions were explored. Firstly, each of 25 compounds was glucosylated with UDP-Glc. Under the action of OcUGT1, five steroids (testosterone, deoxycorticosterone, hydrocortisone, estradiol, and 4-androstenediol) were glucosylated to form corresponding mono-glucosides and biosides. Next, OcUGT1-mediated transglucosylation activity of these compounds with another sugar donor ortho-nitrophenyl- $\beta$-D-glucopyranoside ( $o$ NPGlc) was investigated. Results revealed that the same five steroids could be glucosylated to generate mono-glucosides and biosides by OcUGT1 through transglucosylation reactions. These data indicated that OcUGT1-assisted glycodiversification of steroids could be achieved through glucosylation and transglucosylation reactions. These results provide a way to diversify steroidal glycosides, which lays the foundation for the increase of the probability of obtaining active lead compounds.
\end{abstract}

Keywords: glycodiversification; glucosylation; transglucosylation; glycosyltransferase; steroidal glycosides

\section{Introduction}

Steroidal glycosides (SGs) possess broad biological activities, such as anti-inflammatory effect [1,2], anticancer activity [3-5], antifungal property [6-8], and antiviral activity [9,10]. Moreover, steroidal glycosides are able to serve as the precursors of pharmaceutical steroids [11]. These data indicate that steroidal glycosides are a kind of important natural products with pharmaceutical potential. Hence, it is necessary to diversify steroidal glycosides, so as to increase the probability of discovering innovative drugs from steroidal glycosides. The diversification of SGs, namely glycodiversification of steroids, was achieved by chemical and enzymatical strategies.

Glycodiversification is a synthetic process, through which the structural diversity of carbohydrates is expanded [12]. Owing to the structural complexity of SGs, glycodiversification of steroids by chemical synthesis may be a formidable task [12]. Conversely, the enzymatic glycodiversification is becoming a main strategy for diversifying glycosylated natural products due to the great strides made in the generation of glycosyltransferases (GTs) with catalytic promiscuity [13-15]. Glycosyltransferase is the 
major biocatalyst of enzyme-based glycodiversification, transferring sugar moieties from activated donor molecules (such as nucleotide-sugars) to acceptor substrates with a regio- and stereo-selective manner. The glycodiversification of natural products was thus dependent on the promiscuity of gylcosyltransferase. Although many steroidal glycosyltransferases (SGTs) had been isolated from varied species within the last few years [11,16-22], most SGTs had not been fully explored for their glycodiversification potentials, including the multifunctional glycosyltransferase OcUGT1 [23]. In our previous reports, OcUGT1 was characterized to be a UDP-Glc-dependent glycosyltransferase with a catalytic flexibility, catalyzing diverse aglycons to form corresponding glycosides [23,24]. Moreover, OcUGT1 was observed to glycosylate testosterone to generate its glycosides, indicating OcUGT1 was able to act as a SGT [25]. Therefore, it is of great significance to carry out the research of OcUGT1 on glycodiversification of steroids for enriching the steroidal glycosides and expanding the enzymatic tools for glycodiversification of steroids.

Herein, the glycodiversification potential of a purified OcUGT1 towards steroids in both glucosylation and transglucosylation reactions was explored. Results indicated that OcUGT1 was able to attack $17 \beta-\mathrm{OH}$ and the primary hydroxyl group at C-21 position of steroids. Moreover, OcUGT1 was demonstrated to have the ability of multiple glycosylations, accepting its glycosylated products for further attachment, no matter the glycosylation and transglycosylation reactions. Cumulatively, OcUGT1 may be deemed as a potential enzymatic tool for glycodiversification of steroids.

\section{Results and Discussion}

\subsection{Intracellular Expression and Purification of OcUGT1}

The recombinant plasmid pET28a-OcUGT1 were introduced into E. coli BL21 (DE3) harboring a chaperone plasmid pKJE7 for heterologous expression, respectively [23]. The expression procedure was the same as that previously reported [23-26]. The expressed OcUGT1 were verified by $12 \%$ SDS-PAGE electrophoresis where an intense band with $53 \mathrm{kDa}$ were readily visible (Figure S1), suggesting successful expression of OcUGT1.

OcUGT1 was then purified to near homogeneity using an affinity chromatography as described previously [23-26]. The purified protein was quantified to be $10.5275 \mathrm{mg} / \mathrm{mL}$. The purified OcUGT1 was then used as a biocatalyst for the glycodiversification of steroids.

\subsection{OcUGT1-Catalyzed Glucosylation Towards Steroids}

Previous studies had shown that OcUGT1 was able to glycosylate testosterone [23]. The glycodiversification capability of OcUGT1 towards steroids, however, had not been documented. Herein, a total of 25 steroids were used as the substrate to react with OcUGT1 to test the glycodiversification potential of OcUGT1. The results showed that five compounds, namely testosterone (1), deoxycorticosterone (2), hydrocortisone (3), estradiol (4), and 4-androstenediol (5), were able to form new peaks under the catalyzation of OcUGT1.

Two new peaks, $\mathbf{1 a}$ and $\mathbf{1 b}$, appeared after the incubation of testosterone (1) with purified OcUGT1 at $50{ }^{\circ} \mathrm{C}$ for $2.5 \mathrm{~h}$ (Figure $1 \mathrm{~A}$ ), which was consistent with the previous report [25]. Both $\mathbf{1 a}$ and $\mathbf{1 b}$ displayed similar UV spectra with that of testosterone (1), indicating three compounds shared a similar backbone structure (Figure 1C). Metabolites $\mathbf{1 a}$ and $\mathbf{1 b}$ were found with $\mathrm{m} / \mathrm{z}$ of $451.26816[\mathrm{M}+\mathrm{H}]^{+}$ and $613.32037[\mathrm{M}+\mathrm{H}]^{+}$, corresponding to their mono-glucosylation $\left(\mathrm{C}_{25} \mathrm{H}_{38} \mathrm{O}_{7}\right)$ and di-glucosylation $\left(\mathrm{C}_{31} \mathrm{H}_{48} \mathrm{O}_{12}\right)$ of testosterone, respectively (Figure 1D-E). Herein, di-glucosylation refers to testosterone, in principle, that could be glycosylated at two different positions (di-glucoside) or the glycosyl moiety in testosterone mono-glucoside could react with a second molecule of glucose (bioside). Further, 1D-NMR $\left({ }^{1} \mathrm{H}\right.$ - and $\left.{ }^{13} \mathrm{C}-\mathrm{NMR}\right)$ data supported that $\mathbf{1} \mathbf{a}$ and $\mathbf{1} \mathbf{b}$ were monoside and bioside of testosterone (Tables 1 and 2, Figures S2-15), respectively. The locations of glucose group in $\mathbf{1 a}$ and $\mathbf{1 b}$ were determined based on their HMBC data (Figure S5,12). The HMBC correlation at $\delta \mathrm{H} / \delta \mathrm{C} 4.32\left(\mathrm{H}-1^{\prime}\right) / 89.6(\mathrm{C}-17)$ demonstrated that Glc 1 was located at $\mathrm{C}-17$ of the testosterone aglycone, which was consistent 
with our previous study [25]. Another HMBC correlation at $\delta \mathrm{H} / \delta \mathrm{C} 4.35\left(\mathrm{H}-1^{\prime \prime}\right) / 69.7\left(\mathrm{C}-6^{\prime}\right)$ confirmed that Glc 2 was located at C-6 of Glc 1 . Correlations also observed in the HMBC spectrum of $\mathbf{1 b}$ between the H-6 ${ }^{\prime} \mathrm{a}$ of Glc 1 at $\delta \mathrm{H} 4.12$ and C-1 of Glc 2(C-1") at $\delta \mathrm{c} 104.8, \mathrm{H}-6^{\prime} \mathrm{b}$ of Glc 1 at $\delta \mathrm{H} 3.79$, and C-1 of Glc 2(C-1") at $\delta c 104.8$ established Glc 2 was located at C- $6^{\prime}-\mathrm{OH}$ of the mono-glucoside. These data collectively assigned $\mathbf{1 a}$ and $\mathbf{1 b}$ to be testosterone $17-O-\beta-\mathrm{D}$-glucoside (T-17-G) (Table 1 , Figures S2-S8) and testosterone 17-O- $\beta$-D-glucopyranosyl-( $1 \rightarrow 6)-\beta$-D-glucopyranoside (T-17-GG) (Table 2, Figures S9-S15). Previously, only the mono-glucoside of testosterone catalyzed by OcUGT1 had been identified exactly [25]. Herein, besides the mono-glycoside, the structure of testosterone bioside has been identified to testosterone $17-O-\beta$-D-glucopyranosyl-( $1 \rightarrow 6)-\beta$-D-glucopyranoside (testosterone 17-O-gentobioside), which is a new compound. These results collectively indicated that OcUGT1 was able to exert glucosylation on the 17 $\beta$-position of testosterone (Figure 1B). When epitestosterone (7), an epimer of testosterone (1), was incubated with OcUGT1, no new peaks were present in the reaction mixture, suggesting OcUGT1 had no activity towards the hydroxyl group on $17 \alpha$ position of epitestosterone (7). This notion was further confirmed that OcUGT1 had no effect on $17 \alpha-\mathrm{OH}$ of $17 \alpha$-hydroxypregnenolone (11) and $17 \alpha$-hydroxyprogesterone (15). These data indicated that the OcUGT1-catalyzed glucosylation is a stereospecific reaction, in which the hydroxyl groups with $\beta$-configuration can be specifically glucosylated. However, OcUGT1-mediated glucosylation towards $17 \beta-\mathrm{OH}$ could be hindered by the introduction of an ethynyl group. Therefore, no products were yielded in OcUGT1-assisted glucosylation towards ethisterone (14). 

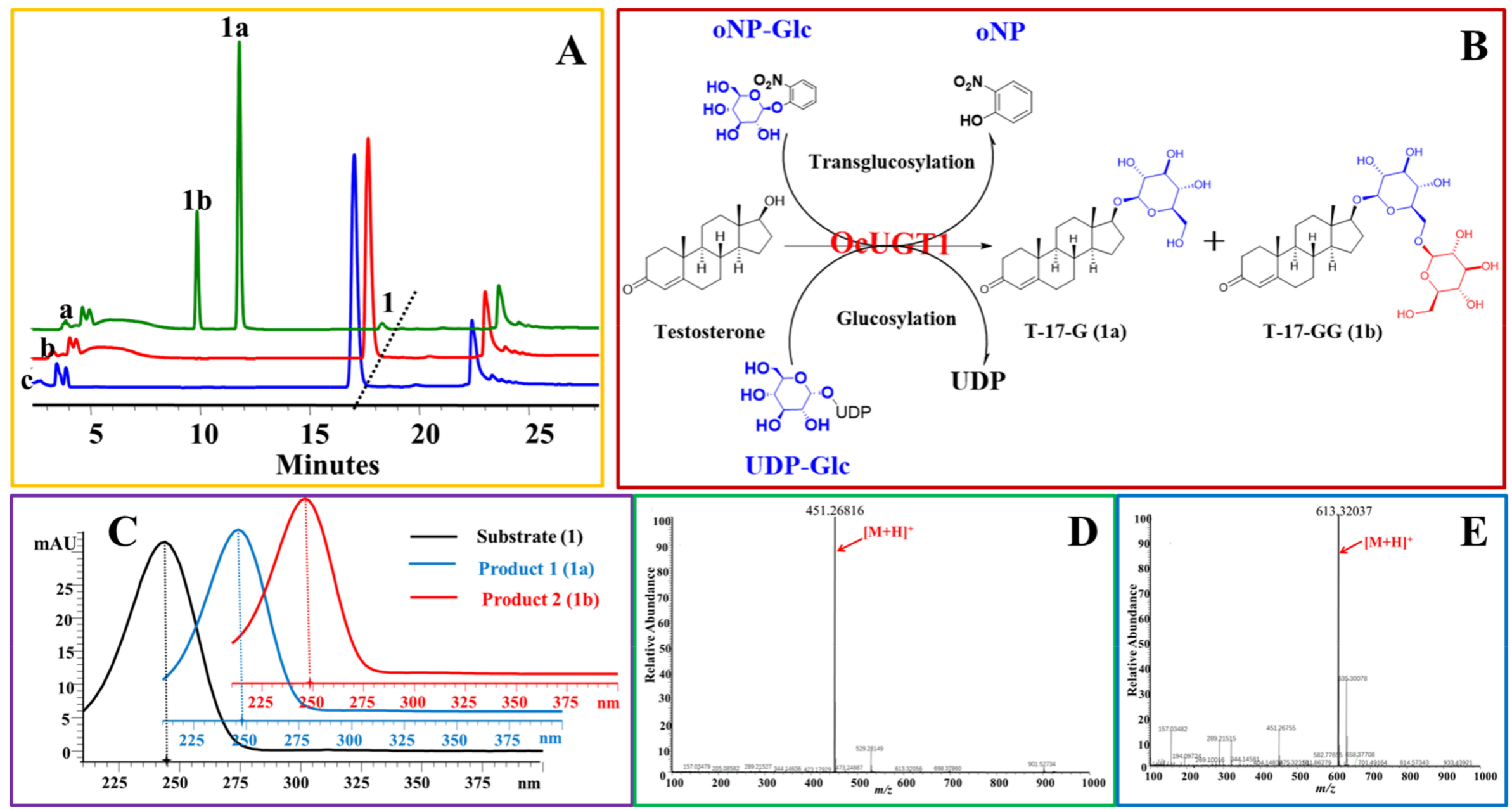

Figure 1. OcUGT1-catalyzed glucosylation of testosterone (1). (A) HPLC profiles of testosterone (1) glucosylation. (a) the reaction mixture of testosterone (1) with the purified OcUGT1; (b) the reaction mixture of testosterone (1) without the purified OcUGT1; (c) the authentical standard testosterone (1); $\mathbf{1}$, 1a, and $\mathbf{1 b}$ refer to testosterone (1) and its mono-glucoside and bioside, respectively. (B) OcUGT1-mediated glucosylation of testosterone. (C) Ultraviolet (UV) spectra of testosterone (1) and its glucosides. (D) HR-ESI-MS spectrum of T-17-G (1a). (E) HR-ESI-MS spectrum of T-17-GG (1b). 
Table 1. NMR spectroscopic data for compound 1a (T-17-G), in $\mathrm{CD}_{3} \mathrm{OD}$ ( $\delta$ in ppm, $J$ in $\mathrm{Hz}$ ).

\begin{tabular}{|c|c|c|}
\hline \multicolumn{3}{|r|}{ Compound 1a } \\
\hline Position & $\delta_{C}$ & $\delta_{H}$ \\
\hline 1 & 36.7 & $\begin{array}{c}1.72(1 \mathrm{H}, \mathrm{ddd}, J=14.4,12.6,4.2 \mathrm{~Hz}, \mathrm{H}-1 \alpha) \\
2.10(1 \mathrm{H}, \mathrm{ddd}, J=12.6,4.8,3.0 \mathrm{~Hz}, \mathrm{H}-1 \beta)\end{array}$ \\
\hline 2 & 34.7 & $\begin{array}{c}2.27(1 \mathrm{H}, \mathrm{ddd}, J=16.2,4.2,3.0 \mathrm{~Hz}, \mathrm{H}-2 \alpha) \\
2.46(1 \mathrm{H}, \mathrm{ddd}, J=16.2,14.4,4.8 \mathrm{~Hz}, \mathrm{H}-2 \beta)\end{array}$ \\
\hline 3 & 202.3 & - \\
\hline 4 & 124.1 & $5.70(1 \mathrm{H}, \mathrm{s}, \mathrm{H}-4)$ \\
\hline 5 & 175.2 & - \\
\hline 6 & 33.9 & $\begin{array}{l}2.32(1 \mathrm{H}, \mathrm{ddd}, J=14.4,4.2,2.4 \mathrm{~Hz}, \mathrm{H}-6 \alpha) \\
2.50(1 \mathrm{H}, \mathrm{ddd}, J=14.4,13.8,5.4 \mathrm{~Hz}, \mathrm{H}-6 \beta)\end{array}$ \\
\hline 7 & 32.8 & $\begin{array}{c}1.04(1 \mathrm{H}, \text { dddd }, J=13.8,12.6,11.4,4.2 \mathrm{~Hz}, \mathrm{H}-7 \alpha) \\
2.02(1 \mathrm{H}, \mathrm{dddd}, J=12.6,5.4,3.0,2.4 \mathrm{~Hz}, \mathrm{H}-7 \beta)\end{array}$ \\
\hline 8 & 36.8 & $1.68(1 \mathrm{H}, \mathrm{dddd}, J=11.4,10.8,10.2,3.0 \mathrm{~Hz}, \mathrm{H}-8)$ \\
\hline 9 & 55.5 & $0.97(1 \mathrm{H}, \mathrm{ddd}, J=12.0,10.2,4.2 \mathrm{~Hz}, \mathrm{H}-9)$ \\
\hline 10 & 40.0 & - \\
\hline 11 & 21.8 & $\begin{array}{c}1.62(1 \mathrm{H}, \text { dddd }, J=13.2,4.2,4.2,3.0 \mathrm{~Hz}, \mathrm{H}-11 \alpha) \\
1.50(1 \mathrm{H}, \mathrm{dddd}, J=13.8,13.2,12.0,4.2 \mathrm{~Hz}, \mathrm{H}-11 \beta)\end{array}$ \\
\hline 12 & 38.5 & $\begin{array}{c}1.21(1 \mathrm{H}, \mathrm{ddd}, J=13.8,12.3,4.2 \mathrm{~Hz}, \mathrm{H}-12 \alpha) \\
1.89(1 \mathrm{H}, \mathrm{ddd}, J=12.3,4.2,3.0 \mathrm{~Hz}, \mathrm{H}-12 \beta)\end{array}$ \\
\hline 13 & 44.2 & - \\
\hline 14 & 51.7 & $1.01(1 \mathrm{H}, \mathrm{ddd}, J=12.3,10.8,7.2 \mathrm{~Hz}, \mathrm{H}-14)$ \\
\hline 15 & 24.2 & $\begin{array}{c}1.64(1 \mathrm{H}, \text { dddd }, J=12.6,9.6,7.2,3.6 \mathrm{~Hz}, \mathrm{H}-15 \alpha) \\
1.32(1 \mathrm{H}, \mathrm{dddd}, J=12.6,12.3,12.0,6.0 \mathrm{~Hz}, \mathrm{H}-15 \beta)\end{array}$ \\
\hline 16 & 29.8 & $\begin{array}{c}1.60(1 \mathrm{H}, \text { dddd }, J=13.8,12.0,8.4,3.6 \mathrm{~Hz}, \mathrm{H}-16 \alpha) \\
2.06(1 \mathrm{H}, \mathrm{dddd}, J=13.8,9.6,9.0,6.0 \mathrm{~Hz}, \mathrm{H}-16 \beta)\end{array}$ \\
\hline 17 & 89.6 & $3.76(1 \mathrm{H}, \mathrm{dd}, J=9.0,8.4 \mathrm{~Hz}, \mathrm{H}-17)$ \\
\hline 18 & 12.0 & $0.90(3 \mathrm{H}, \mathrm{s}, \mathrm{H}-18)$ \\
\hline 19 & 17.7 & $1.24(3 \mathrm{H}, \mathrm{s}, \mathrm{H}-19)$ \\
\hline $1^{\prime}$ & 104.7 & $4.32\left(1 \mathrm{H}, \mathrm{d}, J=7.8 \mathrm{~Hz}, \mathrm{H}-1^{\prime}\right)$ \\
\hline $2^{\prime}$ & 75.4 & $3.15\left(1 \mathrm{H}, \mathrm{dd}, J=9.0,7.8 \mathrm{~Hz}, \mathrm{H}-2^{\prime}\right)$ \\
\hline $3^{\prime}$ & 77.9 & $3.21\left(1 \mathrm{H}, \mathrm{t}, J=9.0 \mathrm{~Hz}, \mathrm{H}-3^{\prime}\right)$ \\
\hline $4^{\prime}$ & 71.7 & $3.27\left(1 \mathrm{H}, \mathrm{dd}, J=9.0,8.4 \mathrm{~Hz}, \mathrm{H}-4^{\prime}\right)$ \\
\hline $5^{\prime}$ & 78.2 & $3.33\left(1 \mathrm{H}, \mathrm{dd}, J=8.4,5.4 \mathrm{~Hz}, \mathrm{H}-5^{\prime}\right)$ \\
\hline $6^{\prime}$ & 62.8 & $\begin{array}{l}3.86\left(1 \mathrm{H}, \mathrm{dd}, J=12.0,2.4 \mathrm{~Hz}, \mathrm{H}-6^{\prime} \mathrm{a}\right) \\
3.65\left(1 \mathrm{H}, \mathrm{dd}, J=12.0,5.4 \mathrm{~Hz}, \mathrm{H}-6^{\prime} \mathrm{b}\right)\end{array}$ \\
\hline
\end{tabular}

Table 2. NMR spectroscopic data for compound $\mathbf{1 b}$ (T-17-GG) in $\mathrm{CD}_{3} \mathrm{OD}(\delta$ in ppm, $J$ in $\mathrm{Hz}$ ).

\begin{tabular}{ccc}
\hline \multicolumn{3}{c}{ Compound $\mathbf{1 b}$} \\
\hline Position & $\boldsymbol{\delta}_{\mathbf{C}}$ & $\boldsymbol{\delta}_{\mathbf{H}}$ \\
\hline 1 & 36.8 & $\begin{array}{c}1.75(1 \mathrm{H}, \mathrm{ddd}, J=14.4,12.6,4.2 \mathrm{~Hz}, \mathrm{H}-1 \alpha) \\
2.12(1 \mathrm{H}, \mathrm{ddd}, J=12.6,4.8,3.0 \mathrm{~Hz}, \mathrm{H}-1 \beta)\end{array}$ \\
& & $2.27(1 \mathrm{H}, \mathrm{ddd}, J=16.2,4.2,3.0 \mathrm{~Hz}, \mathrm{H}-2 \alpha)$ \\
2 & 34.8 & $2.50(1 \mathrm{H}, \mathrm{ddd}, J=16.2,14.4,4.8 \mathrm{~Hz}, \mathrm{H}-2 \beta)$ \\
3 & 202.4 & - \\
4 & 124.1 & $5.70(1 \mathrm{H}, \mathrm{s}, \mathrm{H}-4)$ \\
5 & 175.3 & - \\
6 & 33.9 & $2.33(1 \mathrm{H}, \mathrm{ddd}, J=14.2,4.2,2.4 \mathrm{~Hz}, \mathrm{H}-6 \alpha)$ \\
& & $2.50(1 \mathrm{H}, \mathrm{ddd}, J=14.2,13.8,5.4 \mathrm{~Hz}, \mathrm{H}-6 \beta)$ \\
7 & 32.8 & $2.08(1 \mathrm{H}, \mathrm{dddd}, J=13.8,12.6,11.4,4.2 \mathrm{~Hz}, \mathrm{H}-7 \alpha)$ \\
8 & 36.8 & $1.70(1 \mathrm{H}, \mathrm{dddd}, J=12.6,5.4,3.0,2.4 \mathrm{~Hz}, \mathrm{H}-7 \beta)$ \\
9 & 55.4 & $0.99(1 \mathrm{H}, \mathrm{ddd}, J=11.4,10.8,10.2,3.0 \mathrm{~Hz}, \mathrm{H}-8)$ \\
10 & 40.0 & \\
\hline
\end{tabular}


Table 2. Cont.

\begin{tabular}{|c|c|c|}
\hline \multicolumn{3}{|r|}{ Compound $1 \mathrm{~b}$} \\
\hline Position & $\delta_{C}$ & $\delta_{\mathbf{H}}$ \\
\hline 11 & 21.8 & $\begin{array}{c}1.64(1 \mathrm{H}, \text { dddd }, J=13.2,4.2,4.2,3.0 \mathrm{~Hz}, \mathrm{H}-11 \alpha) \\
1.53(1 \mathrm{H}, \text { dddd } J=13.8,13.2,12.0,4.2 \mathrm{~Hz}, \mathrm{H}-11 \beta)\end{array}$ \\
\hline 12 & 38.3 & $\begin{array}{c}1.23(1 \mathrm{H}, \mathrm{ddd}, J=13.8,12.3,4.2 \mathrm{~Hz}, \mathrm{H}-12 \alpha) \\
1.91(1 \mathrm{H}, \mathrm{ddd}, J=12.3,4.2,3.0 \mathrm{~Hz}, \mathrm{H}-12 \beta)\end{array}$ \\
\hline 13 & 44.2 & - \\
\hline 14 & 51.6 & $1.04(1 \mathrm{H}, \mathrm{ddd}, J=12.3,10.8,7.2 \mathrm{~Hz}, \mathrm{H}-14)$ \\
\hline 15 & 24.2 & $\begin{array}{c}1.67(1 \mathrm{H}, \text { dddd }, J=12.6,9.6,7.2,3.6 \mathrm{~Hz}, \mathrm{H}-15 \alpha) \\
1.34(1 \mathrm{H}, \text { dddd, } J=12.6,12.3,12.0,6.0 \mathrm{~Hz}, \mathrm{H}-15 \beta)\end{array}$ \\
\hline 16 & 29.9 & $\begin{array}{c}1.61(1 \mathrm{H}, \text { dddd, } J=13.8,12.0,8.4,3.6 \mathrm{~Hz}, \mathrm{H}-16 \alpha) \\
2.09(1 \mathrm{H}, \mathrm{dddd}, J=13.8,9.6,9.0,6.0 \mathrm{~Hz}, \mathrm{H}-16 \beta)\end{array}$ \\
\hline 17 & 89.7 & $3.79(1 \mathrm{H}, \mathrm{dd}, J=9.0,8.4 \mathrm{~Hz}, \mathrm{H}-17)$ \\
\hline 18 & 12.0 & $0.90(3 \mathrm{H}, \mathrm{s}, \mathrm{H}-18)$ \\
\hline 19 & 17.7 & $1.24(3 \mathrm{H}, \mathrm{s}, \mathrm{H}-19)$ \\
\hline $1^{\prime}$ & 104.8 & $4.44\left(1 \mathrm{H}, \mathrm{d}, J=7.8 \mathrm{~Hz}, \mathrm{H}-1^{\prime}\right)$ \\
\hline $2^{\prime}$ & 75.4 & $3.21\left(1 \mathrm{H}, \mathrm{dd}, J=9.0,7.8 \mathrm{~Hz} \mathrm{H}-2^{\prime}\right)$ \\
\hline $3^{\prime}$ & 77.1 & $3.29\left(1 \mathrm{H}, \mathrm{t}, J=9.0 \mathrm{~Hz}, \mathrm{H}-3^{\prime}\right)$ \\
\hline $4^{\prime}$ & 71.6 & $3.36\left(1 \mathrm{H}, \mathrm{dd}, J=9.0,8.4 \mathrm{~Hz}, \mathrm{H}-4^{\prime}\right)$ \\
\hline $5^{\prime}$ & 78.0 & $3.37\left(1 \mathrm{H}, \mathrm{dd}, J=8.4,5.4 \mathrm{~Hz}, \mathrm{H}-5^{\prime}\right)$ \\
\hline $6^{\prime}$ & 69.7 & $\begin{array}{l}4.12\left(1 \mathrm{H}, \mathrm{dd}, J=12.0,2.4 \mathrm{~Hz}, \mathrm{H}-6^{\prime} \mathrm{a}\right) \\
3.79\left(1 \mathrm{H}, \mathrm{dd}, J=12.0,5.4 \mathrm{~Hz}, \mathrm{H}-6^{\prime} \mathrm{b}\right)\end{array}$ \\
\hline $1^{\prime \prime}$ & 104.8 & $4.35\left(1 \mathrm{H}, \mathrm{d}, J=7.8 \mathrm{~Hz}, \mathrm{H}-1^{\prime \prime}\right)$ \\
\hline $2^{\prime \prime}$ & 75.1 & $3.21\left(1 \mathrm{H}, \mathrm{dd}, J=9.0,7.8 \mathrm{~Hz}, \mathrm{H}-2^{\prime \prime}\right)$ \\
\hline $3^{\prime \prime}$ & 77.1 & $3.29\left(1 \mathrm{H}, \mathrm{t}, J=9.0 \mathrm{~Hz}, \mathrm{H}-3^{\prime \prime}\right)$ \\
\hline $4^{\prime \prime}$ & 71.5 & $3.41\left(1 \mathrm{H}, \mathrm{dd}, J=9.0,8.4 \mathrm{~Hz}, \mathrm{H}-4^{\prime \prime}\right)$ \\
\hline $5^{\prime \prime}$ & 78.0 & $3.37\left(1 \mathrm{H}, \mathrm{dd}, J=8.4,5.4 \mathrm{~Hz}, \mathrm{H}-5^{\prime \prime}\right)$ \\
\hline $6^{\prime \prime}$ & 62.8 & $\begin{array}{l}3.67\left(1 \mathrm{H}, \mathrm{dd}, J=12.0,2.4 \mathrm{~Hz}, \mathrm{H}-6^{\prime \prime} \mathrm{a}\right) \\
3.88\left(1 \mathrm{H}, \mathrm{dd}, J=12.0,5.4 \mathrm{~Hz}, \mathrm{H}-6^{\prime \prime} \mathrm{b}\right)\end{array}$ \\
\hline
\end{tabular}

In addition, the $17 \beta$ hydroxyl group, OcUGT1 was able to transfer glucose to primary hydroxyl group at C-21 position in the side chain of steroids. When deoxycorticosterone (2) was incubated with OcUGT1, two new peaks with similar UV spectra to that of the substrate were present in the mixture (Figure 3). The molecular formula of the major product (2a) was established as $\mathrm{C}_{27} \mathrm{H}_{39} \mathrm{O}_{8}$ by HRESIMS at $m / z 491.26031[\mathrm{M}-\mathrm{H}]^{-}$, corresponding to the mono-glucoside of deoxycorticosterone (2). The minor product (2b) gave a molecular formula of $\mathrm{C}_{33} \mathrm{H}_{49} \mathrm{O}_{13}$ by HRESIMS at $m / z 653.30682[\mathrm{M}-\mathrm{H}]^{-}$, corresponding to the di-glucosylation of deoxycorticosterone (2). Based on the catalytic behavior of OcUGT1 and the fact that deoxycorticosterone contained only one hydroxyl group at C-21 position, the mono-glucoside was deduced to be deoxycorticosterone 21-D-glucoside (Figure 3). Moreover, a mono-glucosylated product was yielded in OcUGT1-guided glucosylation towards hydrocortisone (3) (Figure 4). Both deoxycorticosterone (2) and hydrocortisone (3) have a primary hydroxyl group at C-21 position. The mono-glucosylated hydrocortisone was thus deduced to be hydrocortisone 21-D-glucoside (Figure 4). However, OcUGT1 did not attach the glucosyl group to a secondary hydroxyl group in the side-chain of steroids (cyasterone (19) and 24-epicastasterone (16)).

Moreover, the position of a double bond in steroidal skeleton affected the glycosylation activity of OcUGT1. OcUGT1 was able to glucosylate $17 \beta-\mathrm{OH}$ when a double bond was at the $\Delta 4$ position of a steroid (4-androstenediol (5) and testosterone (1)) (Figures 1 and 2). OcUGT1-directed glucosylation towards $17 \beta-\mathrm{OH}$ did not occur if a double bond was at the $\Delta 5$ position (5-androstenediol (6)). 

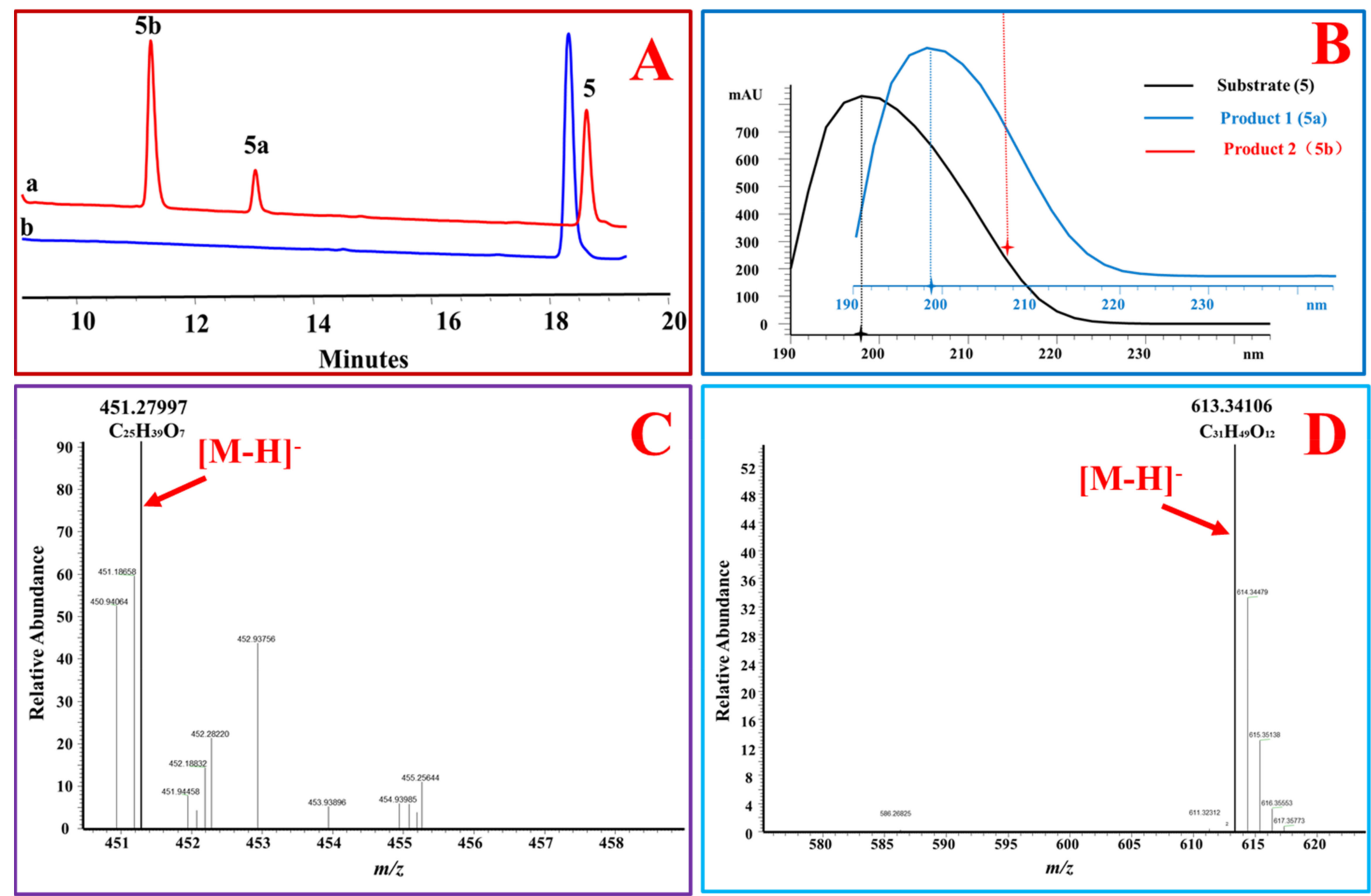

Figure 2. OcUGT1-catalyzed glucosylation of 4-androstenediol (5). (A) HPLC profiles of 4-androstenediol (5) glucosylation. (a) the reaction mixture of 4-androstenediol (5) with the purified OcUGT1; (b) the reaction mixture of 4-androstenediol (5) without the purified OcUGT1; 5, 5a, and 5b refer to 4-androstenediol (5) and its mono-glucoside and bioside, respectively. (B) UV spectra of 4-androstenediol (5) and its glucosides. (C) HR-ESI-MS spectrum of 4-androstenediol mono-glucoside (5a). (D) HR-ESI-MS spectrum of 4-androstenediol bioside (5b). 


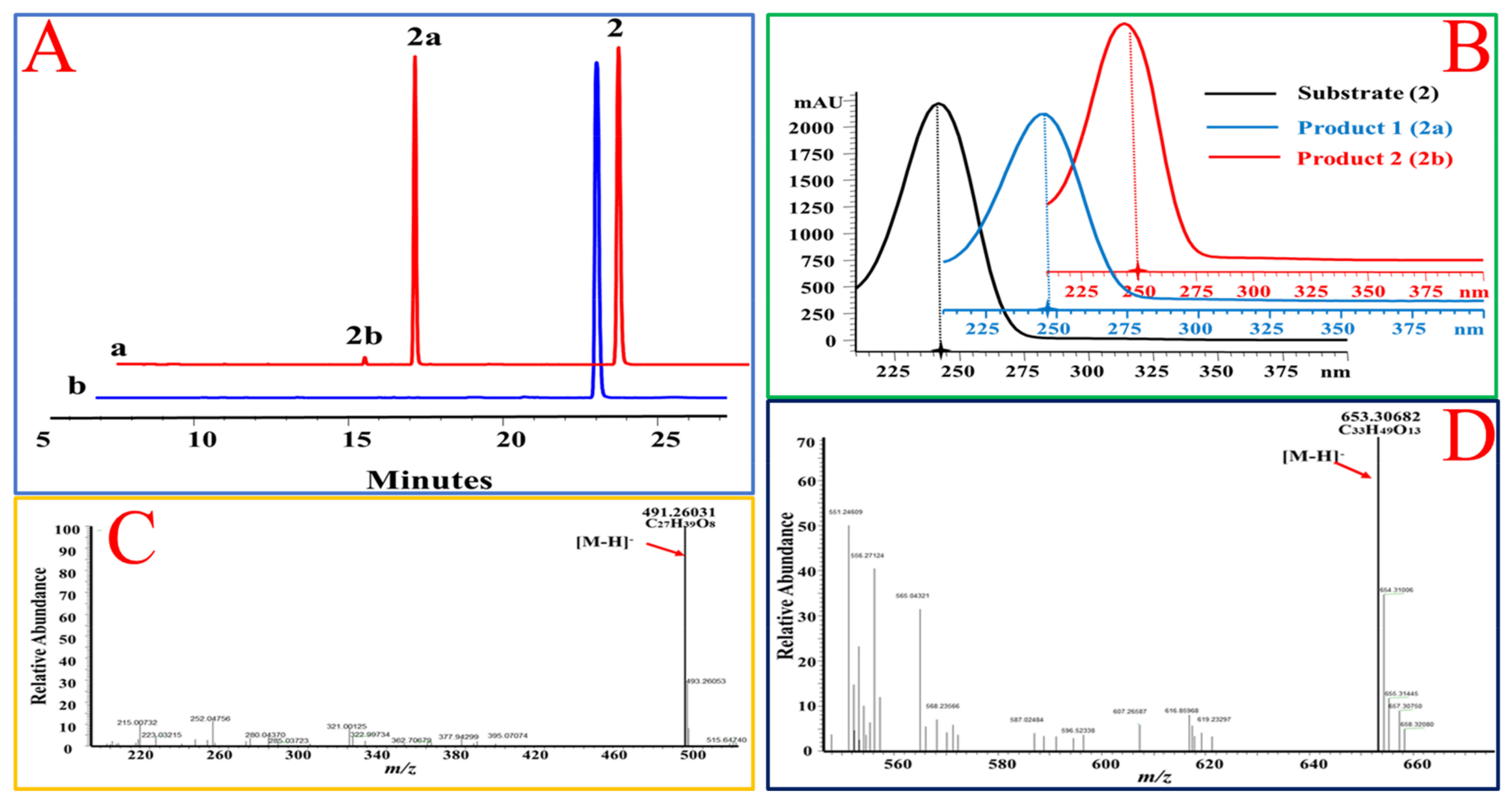

Figure 3. OcUGT1-catalyzed glucosylation of deoxycorticosterone (2). (A) HPLC profiles of deoxycorticosterone (2) glucosylation. (a) The reaction mixture of deoxycorticosterone (2) with the purified OcUGT1; (b) the reaction mixture of deoxycorticosterone (2) without the purified OcUGT1; 2 , 2a, and $\mathbf{2 b}$ refer to deoxycorticosterone (2) and its mono-glucoside and bioside, respectively. (B) UV spectra of deoxycorticosterone (2) and its glucosides. (C) HR-ESI-MS spectrum of deoxycorticosterone mono-glucoside (2a). (D) HR-ESI-MS spectrum of deoxycorticosterone bioside (2b). 


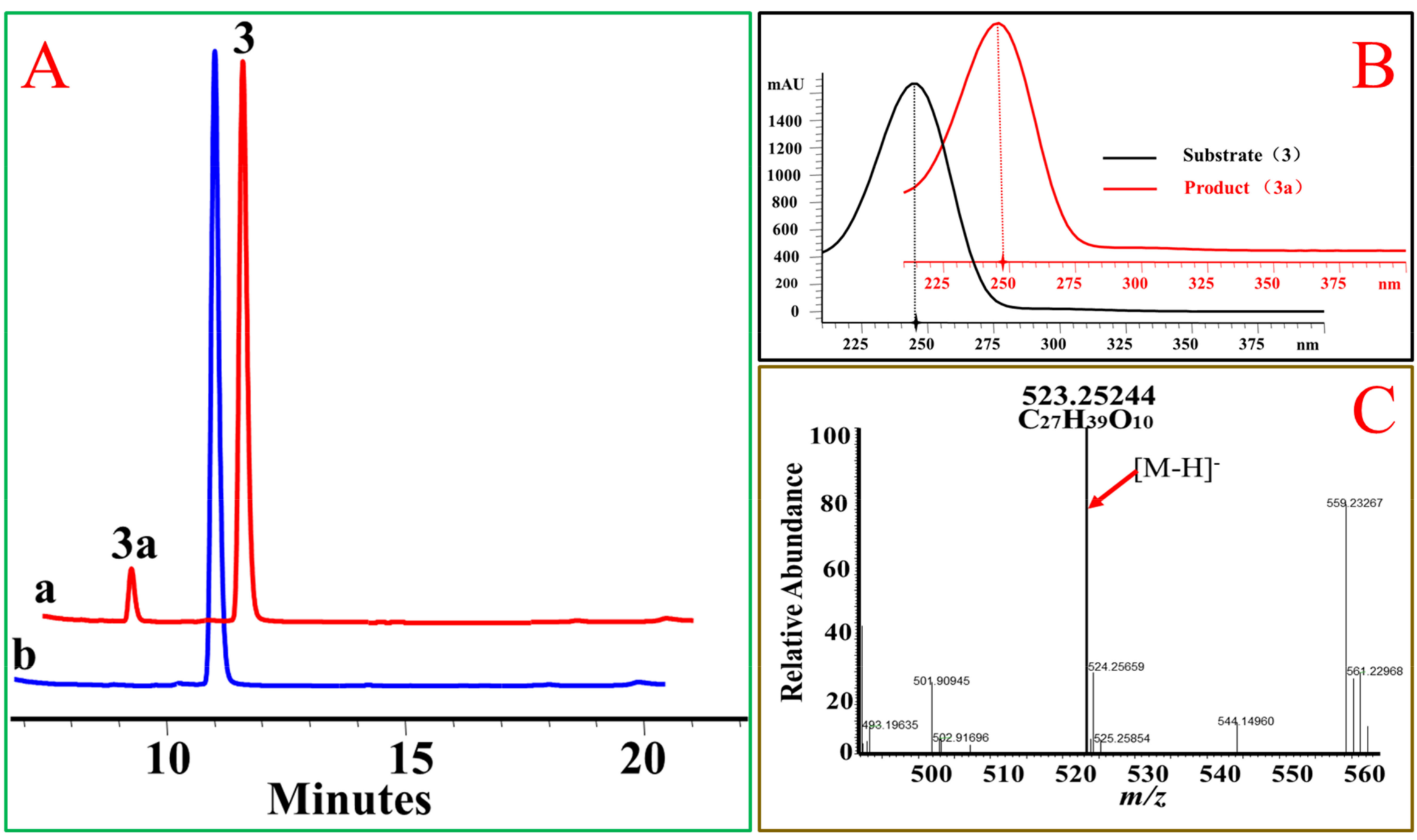

Figure 4. OcUGT1-catalyzed glucosylation towards hydrocortisone (3). (A) HPLC profiles of hydrocortisone (3) glucosylation. (a) the reaction mixture of hydrocortisone (3) with the purified OcUGT1; (b) the reaction mixture of hydrocortisone (3) without the purified OcUGT1. $\mathbf{3}$ and 3a refer to hydrocortisone (3) and its mono-glucoside, respectively. (B) UV spectra of hydrocortisone (3) and its glucosides. (C) HR-ESI-MS spectrum of hydrocortisone mono-glucoside (3a). 
The hydroxyl group at C-3 position of steroids is the site attacked by most known SGTs [11,18]. However, OcUGT1 displayed no activity towards the hydroxyl group at C-3 position, which was evidenced by the fact that OcUGT1 did not react with steroids with $\mathrm{C} 3-\mathrm{OH}$, such as cerberigenin (8), dehydroepiandrosterone (9), pregnenolone (10), 17 $\alpha$-hydroxypregnenolone (11), diosgenin (17), cholesterol (20), $\beta$-sitosterol (21), ergosterol (22), campesterol (23), and cholic acid (24). In addition to the alcoholic hydroxyl group on C-3 position, OcUGT1 cannot glucosylate the phenol hydroxyl group at C-3 position of ethinyl estradiol (12) and estrone (13). Moreover, OcUGT1 was determined to display no glucosylation activity towards hydroxyl groups at C-2(24-epicastasterone (16) and cyasterone (19)), C-7(ergosta-5,24(28)-diene-3,7,16-triol (18) and cholic acid (24)), C-11(11ß-hydroxyprogesterone (25)), C-12 (cholic acid (24)), C-14 (cerberigenin (8) and cyasterone (19)), or C-16 (ergosta-5,24(28)-diene-3,7,16-triol (18)) position of steroids. Therefore, the glucosylated product of estradiol (4) with a free phenolic hydroxyl group at C-3 position catalyzed by OcUGT1 was reasonably deduced as estradiol 17-O- $\beta$-D-glucoside (4a) and corresponding bioside (4b) based on the MS data and the catalytic behavior of OcUGT1 (Figure 5). Cumulatively, OcUGT1 was able to attack $17 \beta-\mathrm{OH}$ and the primary hydroxyl group at C-21 position of steroids (Table 3 and Figure 6).

Table 3. Steroids used for OcUGT1-catalyzed glucosylations.

\begin{tabular}{|c|c|c|}
\hline No & Steroid & Reactivity \\
\hline 1 & testosterone & + \\
\hline 2 & deoxycorticosterone & + \\
\hline 3 & hydrocortisone & + \\
\hline 4 & estradiol & + \\
\hline 5 & 4-androstenediol & + \\
\hline 6 & 5-androstenediol & - \\
\hline 7 & epitestosterone & - \\
\hline 8 & cerberigenin & - \\
\hline 9 & dehydroepiandrosterone & - \\
\hline 10 & pregnenolone & - \\
\hline 11 & $17 \alpha$-hydroxypregnenolone & - \\
\hline 12 & ethinyl estradiol & - \\
\hline 13 & estrone & - \\
\hline 14 & ethisterone & - \\
\hline 15 & $17 \alpha$-hydroxyprogesterone & - \\
\hline 16 & 24-epicastasterone & - \\
\hline 17 & diosgenin & - \\
\hline 18 & ergosta-5,24(28)-diene-3,7,16-triol & - \\
\hline 19 & cyasterone & - \\
\hline 20 & cholesterol & - \\
\hline 21 & $\beta$-sitosterol & - \\
\hline 22 & ergosterol & - \\
\hline 23 & campesterol & - \\
\hline 24 & cholic acid & - \\
\hline 25 & $11 \beta$-hydroxyprogesterone & - \\
\hline
\end{tabular}

"+" and "-" indicate reactivity and no reactivity with OcUGT1. 


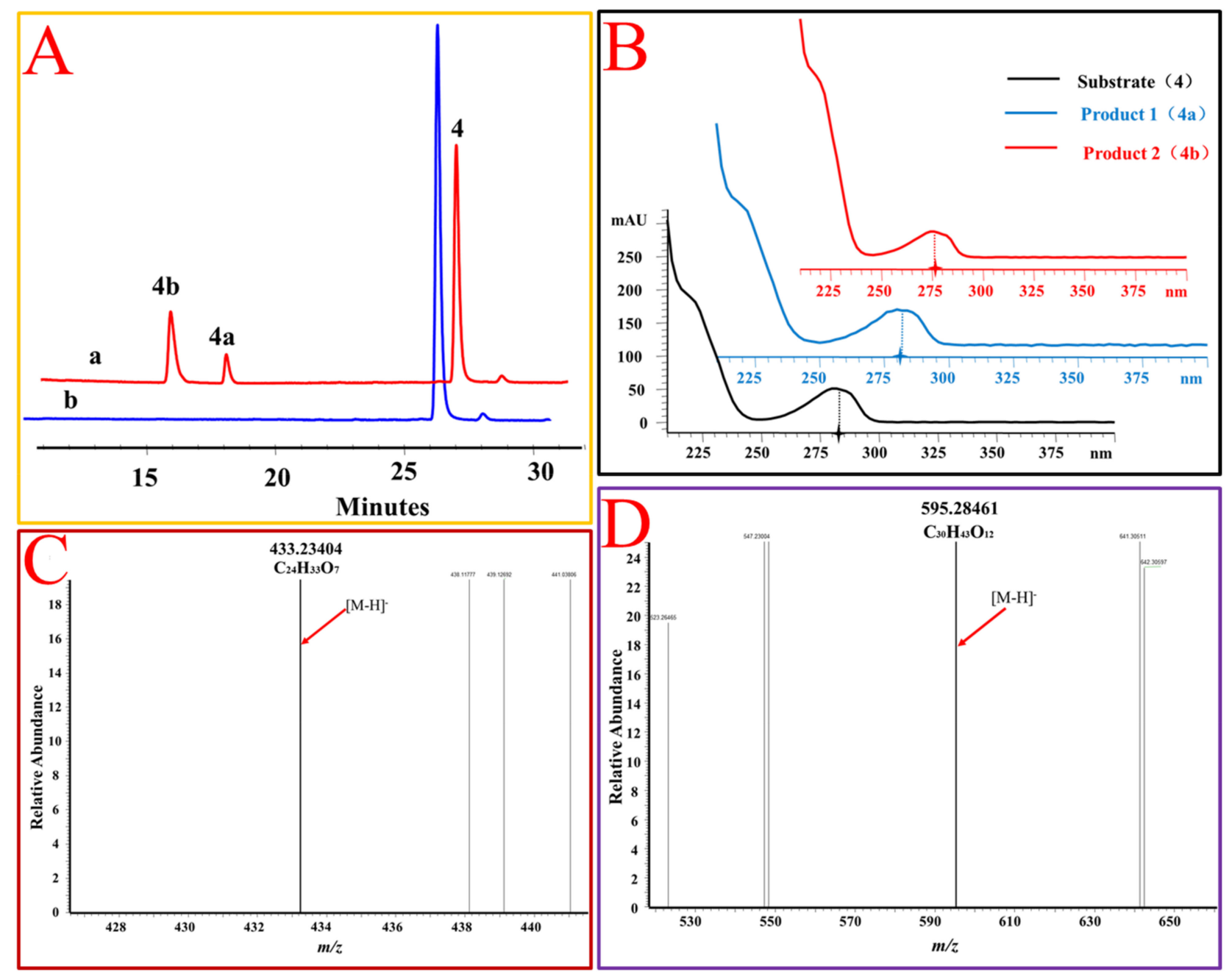

Figure 5. OcUGT1-catalyzed glucosylation of estradiol (4). (A) HPLC profiles of estradiol (4) glucosylation. (a) the reaction mixture of estradiol (4) with the purified OcUGT1; (b) the reaction mixture of estradiol (4) without the purified OcUGT1. 4, 4a, and $\mathbf{4 b}$ refer to estradiol (4) and its mono-glucoside and bioside, respectively. (B) UV spectra of estradiol (4) and its glucosides. (C) HR-ESI-MS spectrum of estradiol mono-glucoside (4a). (D) HR-ESI MS spectrum of estradiol bioside (4b). 


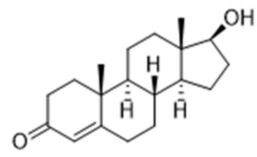

(1)

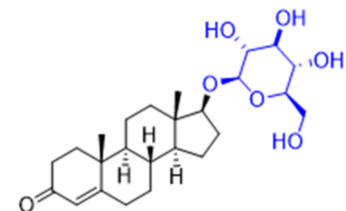

(1a)

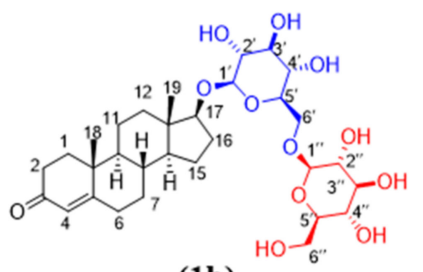

(1b)

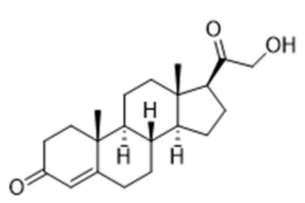

(2)

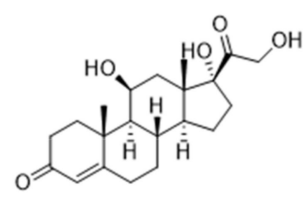

(3)

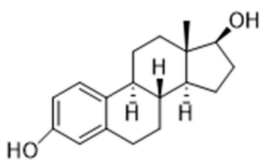

(4)

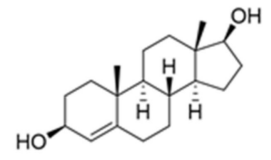

(5)

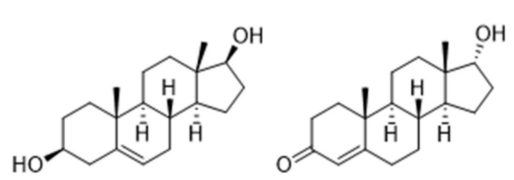

(6)

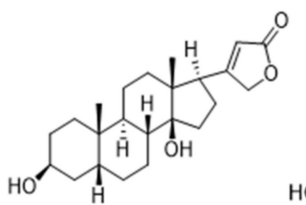

(8)

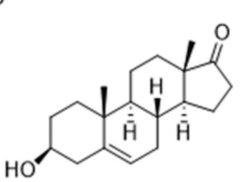

(9)<smiles>CC(=O)C1CCC2[C@H]3C=C4C[C@@H](O)CC[C@]4(C)[C@H]3CC[C@@]12C</smiles>

(10)

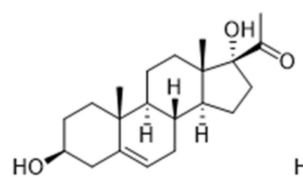

(11)

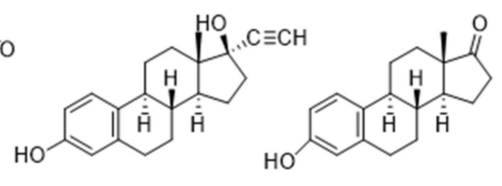

(12)
(13)<smiles>C=C[C@]1(O)CC[C@H]2[C@@H]3CCC4=CC(=O)CC[C@]4(C)[C@H]3CC[C@H]21</smiles>

(14)<smiles>CC(=O)C1(O)CCC2C3CCC4=CC(=O)CCC4(C)C3CCC21C</smiles>

(15)

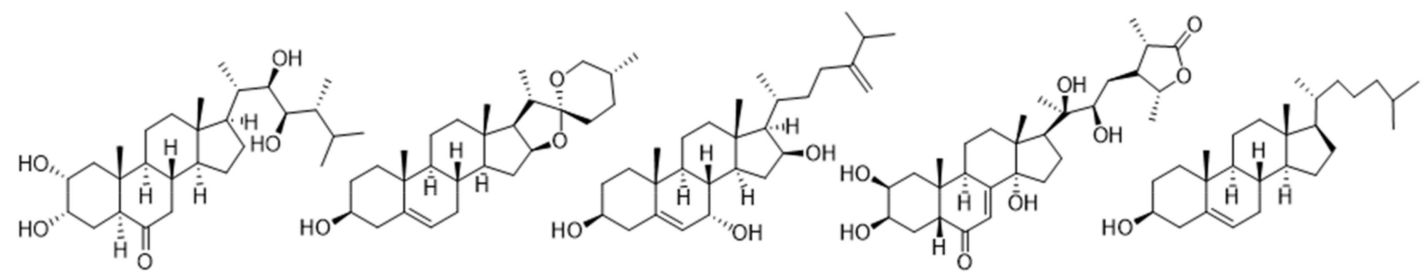

(16)

(17)

(18)

(19)

(20)

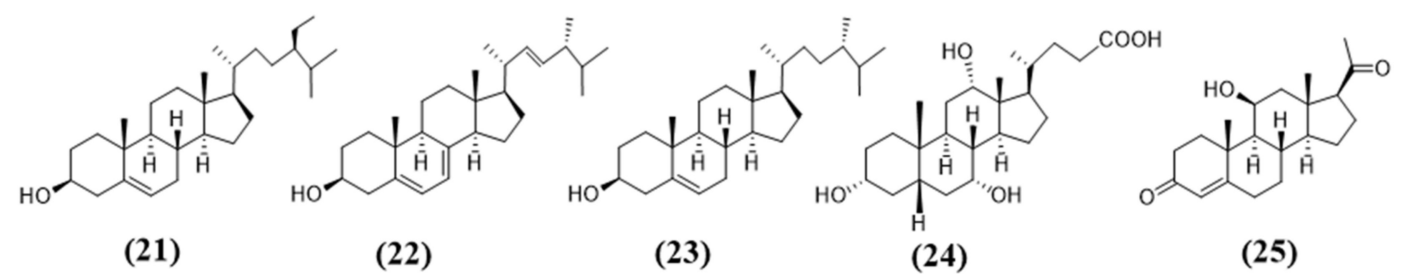

Figure 6. Steroidal substrates used in this study.

\subsection{OcUGT1-Mediated Transglucosylation Towards Steroids}

In OcUGT1-directed glucosylations towards steroids, an expensive compound UDP-Glc (2450 ¥/g, J\&K Scientific Ltd.) was used as the sugar donor, which was not conducive to the diversification of steroidal glycosides. Therefore, OcUGT1-mediated transglycosylations using a cheaper aryl-substituted glycoside $o$ NPGlc (770 $¥ / \mathrm{g}$, J\&K Scientific Ltd.) as a sugar donor were tested in this investigation. Under the action of OcUGT1, each of the 25 compounds reacted with oNPGlc separately. When testosterone (1) was incubated with oNPGlc, OcUGT1 catalyzed the sugar transfer from oNPGlc to 
testosterone, forming testosterone mono-glucoside T-17-G (1a). Furthermore, OcUGT1 transferred the sugar group from $o$ NPGlc to the glucosyl moiety of T-17-G (1a) to form the corresponding testosterone bioside T-17-GG (1b). Meanwhile, oNPGlc was deglucosylated to form $o$ NP (Figure 7A). These data indicated that OcUGT1 has the ability of multiple glucosylations in the process of transglucosylation, which was the same as that of glucosylation reactions. This notion was further verified by the transglucosylation reactions between oNPGlc and deoxycorticosterone (2) (Figure 7B), estradiol (4) (Figure 7D) or 4-androstenediol (5) (Figure 7E), in which steroidal mono-glucosides and biosides were generated. Moreover, OcUGT1-assisted transglycosylation towards hydrocortisone (3) resulted in only one mono-glucoside, consistent with that of OcUGT1-catalyzed hydrocortisone (3) glucosylation (Figure 7C). With the exception of the above five steroids, the remaining 20 compounds had no reactivity with oNPGlc. Thus, the substrate spectrum of OcUGT1-assisted transglucosylation is consistent with that of glucosylation reactions. In addition, the product diversity generated through transglucosylations is the same as that of glucosylations. These data collectively revealed that both transglucosylation and glucosylation can achieve a considerable glycodiversification of steroids. 

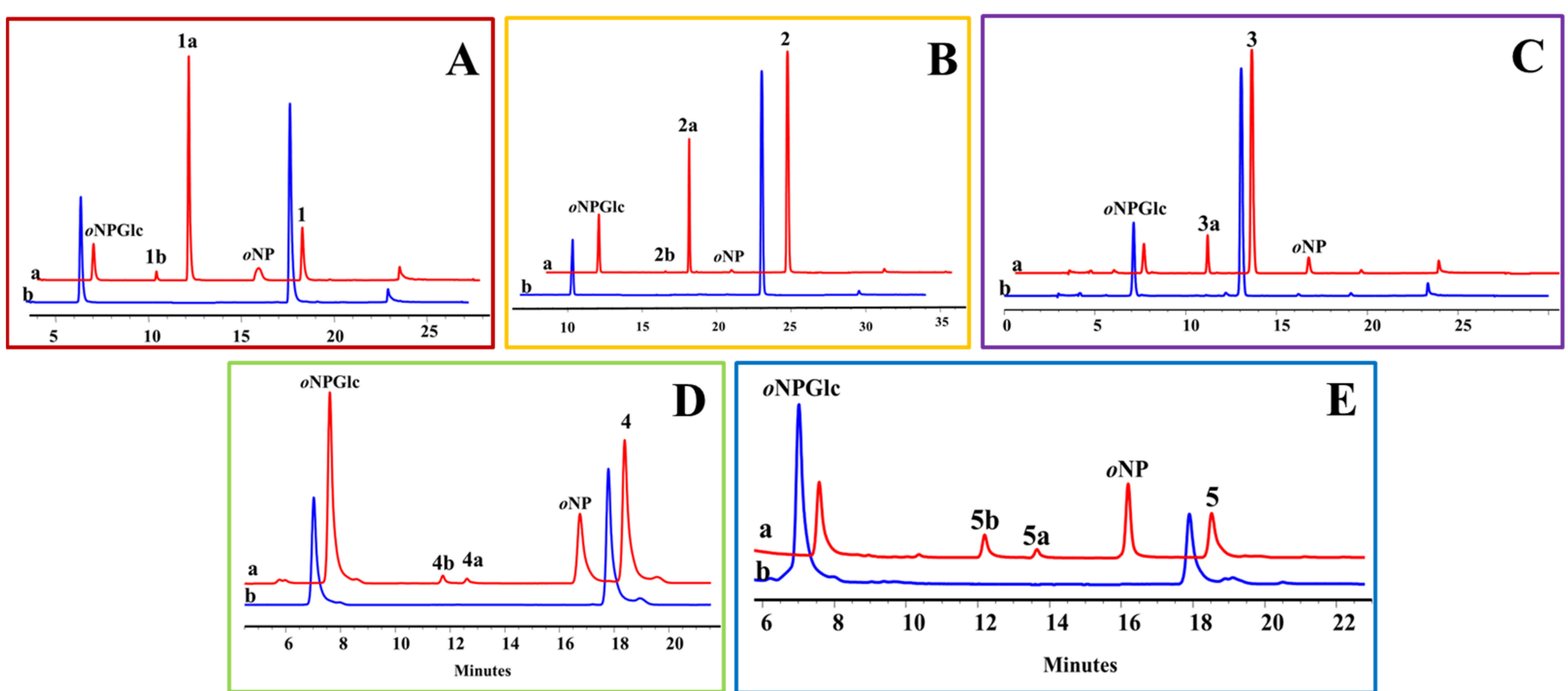

Figure 7. HPLC profiles of OcUGT1-assisted transglucosylation between oNPGlc and testosterone (A), deoxycorticosterone (B), hydrocortisone (C), estradiol (D) or 4-androstenediol (E). (a) Transglucosylation reaction with purified OcUGT1; (b) transglucosylation reaction without purified OcUGT1. 


\section{Materials and Methods}

\subsection{Plasmids and Strains}

The expression plasmid pET28a-OcUGT1, constructed in our previous report [23], was used for heterologous expression of the OcUGT1 gene. The Escherichia coli strains Trans1-T1 and BL21 (DE3) (TransGen Biotech, Beijing, China) were used as the hosts for plasmids amplification and heterologous expression, respectively.

\subsection{Chemicals and Reagents}

Steroidal substrates summarized in Figure 6 were purchased from BioBioPha Co. Ltd. (Kunming, China), Push Bio-technology Co. Ltd. (Chengdu, China), and J\&K Scientific Ltd. (Beijing, China), respectively. These steroids were dissolved in dimethyl sulfoxide (DMSO) for glucosylation and transglucosylation assays unless otherwise noted.

\subsection{Intracellular Expression and Purification of OcUGT1}

The plasmid pET28a-OcUGT1 was introduced into a BL21 (DE3) harboring a chaperone plasmid pKJE7 for intracellular expression of OcUGT1 as described previously [23]. The resultant OcUGT1 was then purified to near homogeneity [23]. After being quantified by the Bradford method [27], the purified OcUGT1 was used as the biocatalyst for glucosylation and transglucosylation assays of steroids.

\subsection{Assays for Glucosylation Activity}

The purified OcUGT1-catalyzed glucosylation reaction were carried out as previously described [23], with a minor modification. Briefly, OcUGT1-catalyzed glucosylation assays were run in a $100 \mu \mathrm{L}$ reaction containing a $10 \mu \mathrm{L}$ PBS buffer $(0.2 \mathrm{M}, \mathrm{pH} 8.0), 10 \mu \mathrm{L}$ UDPG $(10 \mathrm{mM}), 10 \mu \mathrm{L}$ steroid substrate $(10 \mathrm{mM})$, and $10 \mu \mathrm{L}$ purified OcUGT1. After being run at $50{ }^{\circ} \mathrm{C}$ for $2.5 \mathrm{~h}$, glucosylation reactions were terminated by the addition of $100 \mu \mathrm{L}$ methanol and $10 \mu \mathrm{L}$ glacial acetic acid. The reaction mixture was then centrifuged at $12,000 \times \mathrm{g}$ for $5 \mathrm{~min}$ and the resultant supernatant was filtered through a $0.22 \mu \mathrm{m}$ filter. The filtered supernatant was directly analyzed by high-performance liquid chromatography (HPLC) as described previously [25].

\subsection{Assays for OcUGT1-Catalyzed Transglucosylation Action}

The procedure of OcUGT1-assisted transglucosylation actions was the same as described previously [23], with a minor modification. Transglucosylation reactions were performed in a total volume of $100 \mu \mathrm{L}$ harboring $10 \mu \mathrm{L}$ PBS buffer $(0.2 \mathrm{M}, \mathrm{pH} 6.0), 10 \mu \mathrm{L} o \mathrm{NPGlc}$ (ortho-nitrophenyl- $\beta$-D-glucopyranoside, $10 \mathrm{mM}), 10 \mu \mathrm{L}$ steroid substrate $(10 \mathrm{mM})$, and $10 \mu \mathrm{L}$ purified OcUGT1. Transglucosylation reactions lasted overnight at $37^{\circ} \mathrm{C}$. The reaction termination and HPLC measurement of the reaction mixtures were the same as those of glucosylation reactions.

\subsection{Analyses and Structural Identification of Steroidal Glucosides}

The analyses and structural identification of metabolites were performed by the combinational use of HPLC, high resolution electrospray ionization mass spectroscopy (HR-ESI-MS), and nuclear magnetic resonance (NMR), as described previously [3,11,23,25,28]. Briefly, analytical HPLC was performed in an Agilent HPLC 1200 system (Agilent, Waldbronn, Germany) equipped with a SilGreen C18 column $(250 \times 4.6 \mathrm{~mm}$ id, $5 \mu \mathrm{m}$ particle size). The mobile phase was composed of $0.1 \%$ trifluoroacetic acid in $\mathrm{H}_{2} \mathrm{O}$ (solvent $\mathrm{A}$ ) and acetonitrile (solvent $\mathrm{B}$ ). The gradient elution was as follows: $0-5 \mathrm{~min}, 15 \%$ $\mathrm{B} ; 5-20 \mathrm{~min}, 50 \% \mathrm{~B}$; 20-28 $\mathrm{min}, 100 \% \mathrm{~B}$. The flow rate was $1.0 \mathrm{~mL} / \mathrm{min}$. The injection volume was $50 \mu \mathrm{L}$ and the effluents were monitored at $25^{\circ} \mathrm{C}$ by a DAD detector at $243 \mathrm{~nm}$. Glucosylated products were collected on an SEP LC-52 system (SEP. Co. Ltd., Beijing, China) with a YMC C18 preparative 
column $(250 \times 10.0 \mu \mathrm{m}$ ID, $5 \mu \mathrm{m}$; YMC Co. Ltd., Kyoto, Japan). The data collection for HR-ESI-MS were carried out on a Thermo Scientific Exactive Orbitrap LC-Mass spectrometer (Thermo Scientific, Waltham, MA, USA). ${ }^{1} \mathrm{H}-\mathrm{NMR}(600 \mathrm{MHz}),{ }^{13} \mathrm{C}-\mathrm{NMR}(151 \mathrm{MHz})$, and 2D-NMR spectrometric data were recorded with AVANCE III HD 600 NMR spectrometer (Bruker, Rheinstetten, Germany). Chemical shifts are given in $\delta(\mathrm{ppm})$ with the solvent $\left(\mathrm{CD}_{3} \mathrm{OD}-d 4\right)$ peaks as references.

$\begin{array}{ll}\text { Abbreviations } \\ \text { DMSO: } & \text { Dimethyl sulfoxide } \\ \text { GTs: } & \text { Glycosyltransferases } \\ \text { HPLC: } & \text { High-performance liquid chromatography } \\ \text { NMR: } & \text { Nuclear magnetic resonance } \\ \text { oNPGlc: } & \text { oortho-nitrophenyl- } \beta \text {-D-glucopyranoside } \\ \text { SGs: } & \text { Steroidal glycosides } \\ \text { SGTs: } & \text { Steroidal glycosyltransferases } \\ \text { T-17-G: } & \text { Testosterone 17-O- } \beta \text {-glucoside } \\ \text { T-17-GG: } & \text { Testosterone 17-O- } \beta \text {-glucopyranosyl- }(1 \rightarrow 6)-\beta \text {-D-glucopyranoside } \\ \text { UDP-Glc: } & \text { Uridine diphosphate-D-glucose }\end{array}$

Supplementary Materials: The following are available online.

Author Contributions: Investigation, Y.-L.X.; writing-original draft preparation, J.-Q.K.; writing-review and editing, Y.-L.X. and J.-Q.K.; supervision, J.-Q.K.; funding acquisition, J.-Q.K. All authors have read and agreed to the published version of the manuscript.

Funding: This research was funded by National Mega-project for Innovative Drugs, grant number 2018ZX09711001-006, CAMS Innovation Fund for Medical Sciences (CIFMS), grant numbers 2016-I2M-3-012 and 2019-I2M-1-005, Disciplines Construction Project, grant number 201920100801.

Conflicts of Interest: The authors declare no conflict of interest.

\section{References}

1. Zhang, Y.; Yu, H.-Y.; Chao, L.-P.; Qu, L.; Ruan, J.-Y.; Liu, Y.-X.; Dong, Y.-Z.; Han, L.-F.; Wang, T. Anti-inflammatory steroids from the rhizomes of Dioscorea septemloba Thunb. Steroids 2016, 112, 95-102. [CrossRef] [PubMed]

2. Xiang, L.; Wang, Y.; Yi, X.; He, X. Anti-inflammatory steroidal glycosides from the berries of Solanum nigrum L. (European black nightshade). Phytochemistry 2018, 148, 87-96. [CrossRef] [PubMed]

3. Chen, Q.-W.; Zhang, X.; Gong, T.; Gao, W.; Yuan, S.; Zhang, P.-C.; Kong, J.-Q. Structure and bioactivity of cholestane glycosides from the bulbs of Ornithogalum saundersiae Baker. Phytochemistry 2019, 164, $206-214$. [CrossRef] [PubMed]

4. Cimmino, A.; Mathieu, V.; Evidente, M.; Ferderin, M.; Moreno, Y.; Banuls, L.; Masi, M.; De Carvalho, A.; Kiss, R.; Evidente, A. Glanduliferins A and B, two new glucosylated steroids from Impatiens glandulifera, with in vitro growth inhibitory activity in human cancer cells. Fitoterapia 2016, 109, 138-145. [CrossRef]

5. Peng, Y.-r.; Li, Y.-b.; Liu, X.-d.; Zhang, J.-f.; Duan, J.-a. Antitumor activity of C-21 steroidal glycosides from Cynanchum auriculatum Royle ex Wight. Phytomedicine 2008, 15, 1016-1020. [CrossRef]

6. Chludil, H.D.; Seldes, A.M.; Maier, M.S. Antifungal steroidal glycosides from the Patagonian Starfish Anasterias minuta: Structure-activity correlations. J. Nat. Prod. 2002, 65, 153-157. [CrossRef]

7. Favel, A.; Kemertelidze, E.; Benidze, M.; Fallague, K.; Regli, P. Antifungal activity of steroidal glycosides from Yucca gloriosa L. Phytother. Res. 2005, 19, 158-161. [CrossRef]

8. Singh, O.M.; Subharani, K.; Singh, N.; Devi, N.B.; Nevidita, L. Isolation of steroidal glycosides from Solanum xanthocarpum and studies on their antifungal activities. Nat. Prod. Res. 2007, 21, 585-590. [CrossRef]

9. Arthan, D.; Svasti, J.; Kittakoop, P.; Pittayakhachonwut, D.; Tanticharoen, M.; Thebtaranonth, Y. Antiviral isoflavonoid sulfate and steroidal glycosides from the fruits of Solanum torvum. Phytochemistry 2002, 59, 459-463. [CrossRef]

10. Ikeda, T.; Ando, J.; Miyazono, A.; Zhu, X.-H.; Tsumagari, H.; Nohara, T.; Yokomizo, K.; Uyeda, M. Anti-herpes virus activity of Solanum steroidal glycosides. Biol. Pharm. Bull. 2000, 23, 363-364. [CrossRef] 
11. Liu, M.; Kong, J.-Q. The enzymatic biosynthesis of acylated steroidal glycosides and their cytotoxic activity. Acta Pharm. Sin. B 2018, 8, 981-994. [CrossRef] [PubMed]

12. Thibodeaux, C.J.; Melancon, C.E.; Liu, H.W. Unusual sugar biosynthesis and natural product glycodiversification. Nature 2007, 446, 1008-1016. [CrossRef] [PubMed]

13. Sun, L.; Chen, D.; Chen, R.; Xie, K.; Liu, J.; Yang, L.; Dai, J. Exploring the aglycon promiscuity of a new glycosyltransferase from Pueraria lobata. Tetrahedron Lett. 2016, 57, 1518-1521. [CrossRef]

14. Chen, D.; Chen, R.; Wang, R.; Li, J.; Xie, K.; Bian, C.; Sun, L.; Zhang, X.; Liu, J.; Yang, L.; et al. Probing the Catalytic Promiscuity of a Regio- and Stereospecific C-Glycosyltransferase from Mangifera indica. Angew. Chem. Int. Ed. Engl. 2015, 54, 12678-12682. [CrossRef]

15. Xie, K.; Chen, R.; Li, J.; Wang, R.; Chen, D.; Dou, X.; Dai, J. Exploring the catalytic promiscuity of a new glycosyltransferase from Carthamus tinctorius. Org. Lett. 2014, 16, 4874-4877. [CrossRef]

16. Pandey, R.P.; Bashyal, P.; Parajuli, P.; Yamaguchi, T.; Sohng, J.K. Two trifunctional leloir glycosyltransferases as biocatalysts for natural products glycodiversification. Org. Lett. 2019, 21, 8058-8064. [CrossRef]

17. Zhu, X.-L.; Wen, C.; Ye, Q.-M.; Xu, W.; Zou, D.-L.; Liang, G.-P.; Zhang, F.; Chen, W.-N.; Jiang, R.-W. Probing the stereoselectivity of OleD-catalyzed glycosylation of cardiotonic steroids. RSC Adv. 2018, 8, 5071-5078. [CrossRef]

18. Wen, C.; Huang, W.; Zhu, X.-L.; Li, X.-S.; Zhang, F.; Jiang, R.-W. UGT74AN1, a permissive glycosyltransferase from Asclepias curassavica for the regiospecific steroid 3-O-glycosylation. Org. Lett. 2018, 20, 534-537. [CrossRef]

19. Singh, G.; Dhar, Y.V.; Asif, M.H.; Misra, P. Exploring the functional significance of sterol glycosyltransferase enzymes. Prog. Lipid Res. 2018, 69, 1-10. [CrossRef]

20. Chen, L.; Zhang, Y.; Feng, Y. Structural dissection of sterol glycosyltransferase UGT51 from Saccharomyces cerevisiae for substrate specificity. J. Struct. Biol. 2018, 204, 371-379. [CrossRef]

21. Li, K.; Feng, J.; Kuang, Y.; Song, W.; Zhang, M.; Ji, S.; Qiao, X.; Ye, M. Enzymatic synthesis of bufadienolide O-glycosides as potent antitumor agents using a microbial glycosyltransferase. Adv. Synth. Catal. 2017, 359, 3765-3772. [CrossRef]

22. Hoang, N.H.; Hong, S.Y.; Huong, N.L.; Park, J.W. Biochemical characterization of recombinant UDP-glucose:sterol 3-O-glycosyltransferase from Micromonospora rhodorangea ATCC 31603 and enzymatic biosynthesis of sterol-3-O-beta-glucosides. J. Microbiol. Biotechnol. 2016, 26, 477-482. [CrossRef] [PubMed]

23. Yuan, S.; Yin, S.; Liu, M.; Kong, J.-Q. Isolation and characterization of a multifunctional flavonoid glycosyltransferase from Ornithogalum caudatum with glycosidase activity. Sci. Rep. 2018, 8, 5886. [CrossRef] [PubMed]

24. Yuan, S.; Xu, Y.-L.; Yang, Y.; Kong, J.-Q. OcUGT1-catalyzed glucosylation of sulfuretin yields ten glucosides. Catalysts 2018, 8, 416. [CrossRef]

25. Yuan, S.; Yin, S.; Liu, M.; He, J.-M.; Kong, J.-Q. OcUGT1-catalyzed glycosylation of testosterone with alternative donor substrates. Process Biochem. 2018, 73, 82-85. [CrossRef]

26. Yuan, S.; Yang, Y.; Kong, J.-Q. Biosynthesis of 7, 8-dihydroxyflavone glycosides via OcUGT1-catalyzed glycosylation and transglycosylation. J. Asian Nat. Prod. Res. 2018, 20, 662-674. [CrossRef]

27. Liu, M.; Li, L.-N.; Pan, Y.-T.; Kong, J.-Q. cDNA isolation and functional characterization of squalene synthase gene from Ornithogalum caudatum. Protein Expres. Purif. 2017, 130, 63-72. [CrossRef]

28. Liu, X.; Kong, J.-q. Steroids hydroxylation catalyzed by the monooxygenase mutant 139-3 from Bacillus megaterium BM3. Acta Pharm. Sin. B 2017, 7, 510-516. [CrossRef]

Sample Availability: Samples of the compounds used in this study are available from the authors. 